\section{BMJ Open Respiratory Research}

\title{
The effect of tiotropium/olodaterol versus fluticasone propionate/salmeterol on left ventricular filling and lung hyperinflation in patients with COPD
}

Felix Herth, ${ }^{1}$ Jens M Hohlfeld, ${ }^{2,3}$ Johannes Haas, ${ }^{4}$ Alberto de la Hoz, ${ }^{5}$ Xidong Jin, ${ }^{6}$ Karl-Friedrich Kreitner, ${ }^{7}$ Claus Vogelmeier, ${ }^{8}$ Jens Vogel-Claussen, ${ }^{9}$ Henrik Watz ${ }^{10}$

To cite: Herth F, Hohlfeld JM Haas J, et al. The effect of tiotropium/olodaterol versus fluticasone propionate/ salmeterol on left ventricular filling and lung hyperinflation in patients with COPD. BMJ Open Resp Res 2020;7:e000741. doi:10.1136/ bmjresp-2020-000741

Received 18 August 2020 Revised 6 November 2020 Accepted 6 November 2020
Check for updates

(C) Author(s) (or their employer(s)) 2020. Re-use permitted under CC BY-NC. No commercial re-use. See rights and permissions. Published by BMJ.

For numbered affiliations see end of article.

Correspondence to Professor Felix Herth; felix.herth@med.uniheidelberg.de

\section{ABSTRACT}

This exploratory, randomised, double-blind, double-dummy, multicentre, cross-over study explored the effect of 6 weeks of treatment with tiotropium/olodaterol ( $\mathrm{T} / 0$ ) versus fluticasone propionate/salmeterol (F/S) on left ventricular filling in patients with chronic obstructive pulmonary disease with functional residual capacity $(\mathrm{FRC})>120 \%$ predicted and postbronchodilator improvement of FRC $\geq 7.5 \%$. Overall, 76 patients were randomised across nine sites. Treatment with $\mathrm{T} / \mathrm{O}$ or F/S increased left ventricular end-diastolic volume index from baseline (adjusted mean change: T/0: $2.317 \mathrm{~mL} / \mathrm{m}^{2}$, F/S: $2.855 \mathrm{~mL} / \mathrm{m}^{2}$ ), with no statistically significant difference between treatments. However, T/0 resulted in a significantly greater reduction in lung hyperinflation versus F/S (FRC plethysmography absolute change from baseline: F/S: -0.329 L, T/0: $-0.581 \mathrm{~L})$.

\section{INTRODUCTION}

In patients with chronic obstructive pulmonary disease (COPD), cardiovascular disease is serious and prevalent. ${ }^{12}$ Several processes may link COPD and cardiovascular disease, ${ }^{3}$ notably left ventricular (LV) diastolic dysfunction with reduced filling of the left ventricle. ${ }^{45}$ It is proposed that lung hyperinflation results in reduced LV filling, ${ }^{5}$ which is, in turn, associated with reduced exercise capacity and physical activity. ${ }^{45}$

The combination of the long-acting muscarinic antagonist (LAMA)/long-acting $\beta_{2}$-agonist (LABA) tiotropium/olodaterol $(\mathrm{T} / \mathrm{O})$ improves lung hyperinflation and exercise tolerance vs comparators. ${ }^{6}$ Other combinations of LAMA/LABA and LABA/ inhaled corticosteroid (ICS) have been shown to reduce lung hyperinflation and improve LV function versus placebo. ${ }^{78}$

We explored the effect of $\mathrm{T} / \mathrm{O}$ Respimat versus fluticasone propionate/salmeterol $(\mathrm{F} / \mathrm{S})$ Accuhaler on LV filling, assessed by cardiovascular MRI (CMRI). Secondary outcomes included lung hyperinflation and other measures of cardiac function.

\section{METHODS}

\section{Study design}

This was an exploratory, randomised, doubleblind, double-dummy, multicentre, cross-over study (NCT03055988) evaluating the effect of treatment with $\mathrm{T} / \mathrm{O} 5 / 5 \mu \mathrm{g}$ versus $\mathrm{F} / \mathrm{S}$ $1000 / 100 \mu \mathrm{g}$ in patients with COPD. The trial consisted of a run-in period, two 6-week treatment periods with no washout and a follow-up period. During each treatment period, the patient inhaled two puffs from the Respimat inhaler and one inhalation from the Accuhaler in the morning, and one inhalation from the Accuhaler only in the evening; the Respimat inhaler was not used in the evening.

\section{Inclusion/exclusion criteria}

Patients aged $\geq 40-75$ years with a smoking history of $>10$ pack-years were eligible for inclusion if they had postbronchodilator (400 $\mu \mathrm{g}$ salbutamol) forced expiratory volume in $1 \mathrm{~s}\left(\mathrm{FEV}_{1}\right)<70 \%$ predicted normal, with postbronchodilator $\mathrm{FEV}_{1} /$ forced vital capacity (FVC) $<70 \%$. Furthermore, they had to have had a prebronchodilator functional residual capacity (FRC) $>120 \%$ predicted with a postbronchodilator reversibility of at least $7.5 \%$ at screening, in line with the criteria of Stone et al. ${ }^{8}$

Patients were excluded if they had a significant disease other than COPD or a current diagnosis of asthma. Patients who experienced exacerbations in the 6 weeks prior to screening were excluded, as were patients who experienced COPD exacerbations or respiratory tract infections before randomisation. In addition, patients were also excluded if they had a history of myocardial infarction, 


\begin{tabular}{|c|c|}
\hline Characteristic & Total $(\mathrm{N}=76)$ \\
\hline Male, n (\%) & $45(59.2)$ \\
\hline Age, mean (SD), years & $61.9(7.1)$ \\
\hline \multicolumn{2}{|l|}{ Smoking history, n (\%) } \\
\hline Current & $43(56.6)$ \\
\hline Former & $33(43.4)$ \\
\hline BMI, mean (SD), kg/m² & $26(5.6)$ \\
\hline $\begin{array}{l}\text { Postbronchodilator \% predicted normal FEV } \\
\text { (SD) }\end{array}$ & $52.9(12.1)$ \\
\hline $\begin{array}{l}\text { Postbronchodilator \% predicted normal FRC } \\
\text { (SD) }\end{array}$ & $146.8(28.5)$ \\
\hline $\begin{array}{l}\text { Difference between predose and postdose FRC } \\
\% \text { predicted (SD) }\end{array}$ & $-18.3(7.3)$ \\
\hline \multicolumn{2}{|l|}{ GOLD, n (\%) } \\
\hline $\mathrm{I}(\geq 80 \%)$ & $0(0.0)$ \\
\hline II (50-<80\%) & $46(60.5)$ \\
\hline III (30-<50\%) & $26(34.2)$ \\
\hline IV (<30\%) & $4(5.3)$ \\
\hline Cardiac disorders & $15(19.7)$ \\
\hline Chronic cardiac failure & $2(2.6)$ \\
\hline Coronary artery disease & $7(9.2)$ \\
\hline Atrial fibrillation & $1(1.3)$ \\
\hline Hypertension & $47(61.8)$ \\
\hline Diabetes mellitus & $2(2.6)$ \\
\hline $\begin{array}{l}\text { No of subjects with at least one pulmonary } \\
\text { medication at baseline }\end{array}$ & $71(93.4)$ \\
\hline LAMA & $53(69.7)$ \\
\hline SAMA & $3(3.9)$ \\
\hline LABA & $59(77.6)$ \\
\hline SABA & $43(56.6)$ \\
\hline Mucolytics & $2(2.6)$ \\
\hline ICS & $13(17.1)$ \\
\hline Steroids (oral) & $1(1.3)$ \\
\hline
\end{tabular}

$\mathrm{BMI}$, body mass index; $\mathrm{FEV}_{1}$, forced expiratory volume in $1 \mathrm{~s}$; FRC, functional residual capacity; GOLD, Global Initiative for Chronic Obstructive Lung Disease; ICS, inhaled corticosteroid; LABA, longacting $\beta_{2}$-agonist; LAMA, long-acting muscarinic antagonist; SABA short-acting $\beta 2$-agonist; SAMA, short-acting muscarinic antagonist. cerebrovascular event or coronary artery intervention other than coronary artery bypass graft within 1 year of screening, or abnormal ECG with an event such as left bundle branch block and LV hypertrophy. Moreover, patients who had been hospitalised for heart failure within the past year, had current severe heart failure class IV or ejection fraction $\leq 40 \%$ from CMRI baseline assessment, or systolic blood pressure $>140 \mathrm{~mm} \mathrm{Hg}$ and/or diastolic blood pressure $>90 \mathrm{~mm} \mathrm{Hg}$ at screening were also excluded. Patients with stable arterial hypertension controlled under therapy and normotensive at screening could enter the study.

\section{ASSESSMENTS CMRI}

Assessments included CMRI at 1.5 or 3 Tesla lasting $\leq 1$ hour. We assessed cardiac functional parameters and structure using a cardiopulmonary acquisition protocol. Cardiac cine images were acquired in two-chamber, four-chamber and short-axis views. Strain and strain rate of the right and left ventricles were assessed. Aortic distensibility and pulmonary artery pulsatility were derived from cine images acquired at end expiration in planes perpendicular to the thoracic aorta at the level of the pulmonary artery, and perpendicular to the main pulmonary artery. Scans were digitally transferred for blinded central review by an experienced independent reviewer (K-FK).

\section{Lung function}

Body plethysmography, including measurement of FRC, residual volume (RVol), inspiratory capacity (IC), total lung capacity (TLC) and forced spirometry, including measurement of $\mathrm{FEV}_{1}$ and $\mathrm{FVC}$, were performed at screening, baseline and after 6 weeks of treatment, in line with American Thoracic Society/European Respiratory Society standards. ${ }^{9}$ Body plethysmography was followed by forced spirometry measurements. FRC was measured at least three times until three FRC values within 5\% variability were obtained. Lung function was measured at the baseline visit 1 hour prior to inhalation of morning dose. At week 6, lung function was measured 1.5 hours after the morning dose of medication.
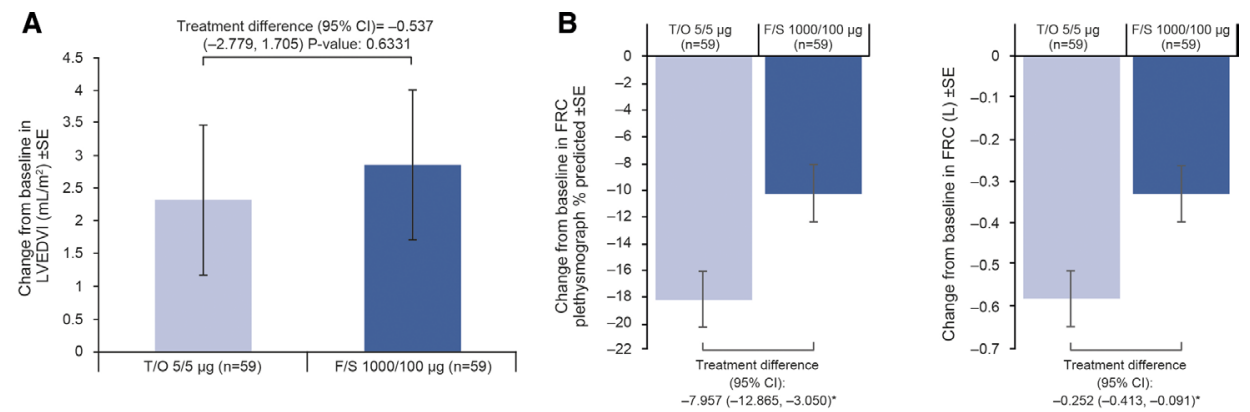

Figure 1 Effect of (A) T/O versus F/S on LVEDVI at week 6 and (B) T/O versus F/S on FRC plethysmograph (percent predicted and absolute change) at week 6 . ${ }^{*} \mathrm{P}<0.01$. F/S, fluticasone propionate/salmeterol; FRC, functional residual capacity; LVEDVI, left ventricular end-diastolic volume index; T/O, tiotropium/olodaterol. 


\section{Endpoints}

The primary endpoint was change from baseline in $\mathrm{LV}$ end-diastolic volume index (LVEDVI) after 6 weeks of treatment with $\mathrm{T} / \mathrm{O}$ versus $\mathrm{F} / \mathrm{S}$. Secondary endpoints were change from baseline at week 6 in aortic distensibility, pulmonary artery pulsatility, FRC, $\mathrm{FEV}_{1}$ and FVC. Further endpoints assessed after 6 weeks of treatment included TLC, RVol and IC.

\section{Statistical analysis}

The full analysis set (FAS) included all randomised patients taking any dose of trial medication, and with both baseline and any evaluable postbaseline measurement for primary or secondary endpoints. Presented results are from FAS patients who did not have an exacerbation during treatment. A restricted maximum likelihoodbased mixed-effect repeated measures model was used for analysis of primary and secondary endpoints. This included treatment and period as fixed effects, patient as a random effect and baseline as covariate. All calculated $p$ values for analyses of secondary endpoints are descriptive as no adjustment for multiple testing was carried out.

Table 2 Cardiac function parameters and arterial stiffness at week 6

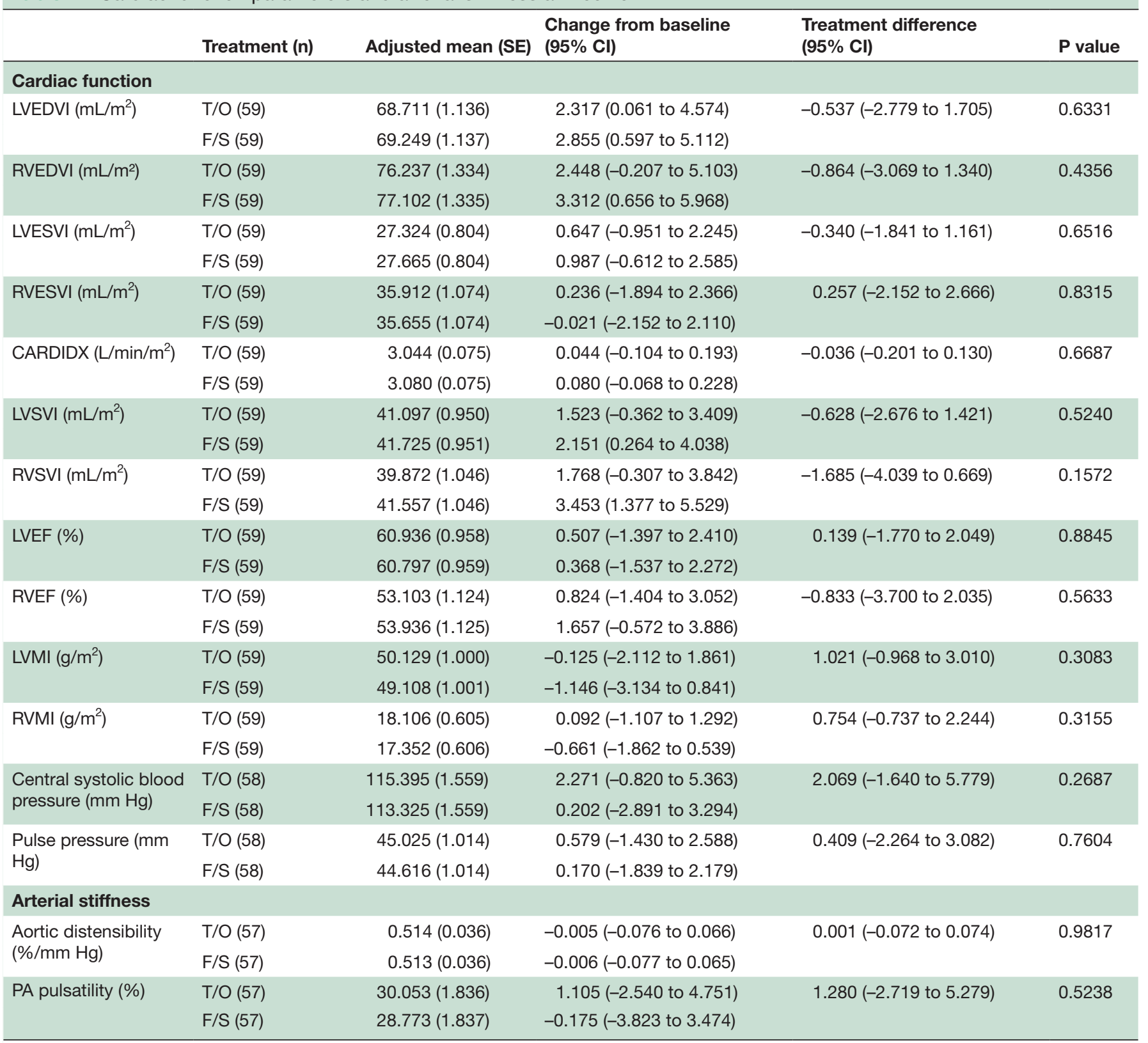

CARDIDX, cardiac index; F/S, fluticasone propionate/salmeterol; LVEDVI, left ventricular end-diastolic volume index; LVEF, left ventricular ejection fraction; LVESVI, left ventricular end-systolic volume index; LVMI, left ventricular mass index; LVSVI, left ventricular stroke volume index; PA, pulmonary artery; RVEDVI, right ventricular end-diastolic volume index; RVEF, right ventricular ejection fraction; RVESVI, right ventricular endsystolic volume index; RVMI, right ventricular mass index; RVSVI, right ventricular stroke volume index; T/O, tiotropium/olodaterol. 


\begin{tabular}{|c|c|c|c|c|c|}
\hline & Treatment (n) & $\begin{array}{l}\text { Adjusted mean } \\
\text { (SE) }\end{array}$ & $\begin{array}{l}\text { Change from baseline } \\
(95 \% \mathrm{Cl})\end{array}$ & $\begin{array}{l}\text { Treatment difference } \\
(95 \% \mathrm{Cl})\end{array}$ & $P$ value \\
\hline \multicolumn{6}{|l|}{ Lung hyperinflation } \\
\hline \multirow{2}{*}{$\begin{array}{l}\text { FRC plethysmography } \\
(\%)\end{array}$} & $\mathrm{T} / \mathrm{O}(59)$ & $146.783(2.065)$ & $-18.168(-22.262$ to -14.074$)$ & \multirow[t]{2}{*}{$-7.957(-12.865$ to -3.050$)$} & \multirow[t]{2}{*}{0.0019} \\
\hline & $\mathrm{F} / \mathrm{S}(59)$ & $154.740(2.066)$ & $-10.211(-14.308$ to -6.113$)$ & & \\
\hline \multirow[t]{2}{*}{$\mathrm{FRC}(\mathrm{L})$} & $\mathrm{T} / \mathrm{O}(59)$ & $4.770(0.069)$ & $-0.581(-0.718$ to -0.443$)$ & \multirow[t]{2}{*}{$-0.252(-0.413$ to -0.091$)$} & \multirow[t]{2}{*}{0.0028} \\
\hline & $\mathrm{F} / \mathrm{S}(59)$ & $5.022(0.069)$ & $-0.329(-0.466$ to -0.191$)$ & & \\
\hline \multirow[t]{2}{*}{ RVol (L) } & $\mathrm{T} / \mathrm{O}(58)$ & $3.742(0.067)$ & $-0.572(-0.704$ to -0.439$)$ & \multirow[t]{2}{*}{$-0.251(-0.409$ to -0.093$)$} & \multirow[t]{2}{*}{0.0024} \\
\hline & $\mathrm{F} / \mathrm{S}(58)$ & $3.993(0.067)$ & $-0.321(-0.453$ to -0.188$)$ & & \\
\hline \multirow[t]{2}{*}{ IC (L) } & $\mathrm{T} / \mathrm{O}(58)$ & $2.066(0.061)$ & 0.320 (0.198 to 0.433$)$ & \multirow[t]{2}{*}{$0.032(-0.084$ to 0.148$)$} & \multirow[t]{2}{*}{0.5832} \\
\hline & $\mathrm{F} / \mathrm{S}(58)$ & $2.035(0.061)$ & $0.289(0.166$ to 0.411$)$ & & \\
\hline \multirow[t]{2}{*}{ TLC (L) } & $\mathrm{T} / \mathrm{O}(58)$ & $6.962(0.071)$ & $-0.206(-0.347$ to -0.066$)$ & \multirow[t]{2}{*}{$-0.184(-0.358$ to -0.010$)$} & \multirow[t]{2}{*}{0.0390} \\
\hline & $\mathrm{F} / \mathrm{S}(58)$ & $7.146(0.071)$ & $-0.023(-0.163$ to 0.118$)$ & & \\
\hline \multicolumn{6}{|l|}{ Spirometry } \\
\hline \multirow[t]{2}{*}{$\mathrm{FEV}_{1}(\mathrm{~L})$} & T/O (59) & $1.725(0.037)$ & $0.339(0.266$ to 0.412$)$ & \multirow[t]{2}{*}{$0.180(0.121$ to 0.240$)$} & \multirow[t]{2}{*}{$<0.0001$} \\
\hline & $\mathrm{F} / \mathrm{S}(59)$ & $1.545(0.037)$ & 0.158 (0.086 to 0.231$)$ & & \\
\hline \multirow[t]{2}{*}{ FVC (L) } & $\mathrm{T} / \mathrm{O}(59)$ & $3.556(0.054)$ & 0.445 (0.338 to 0.552$)$ & \multirow[t]{2}{*}{0.286 (0.171 to 0.400$)$} & \multirow[t]{2}{*}{$<0.0001$} \\
\hline & F/S (59) & $3.270(0.054)$ & $0.159(0.052$ to 0.266$)$ & & \\
\hline
\end{tabular}

$\mathrm{FEV}_{1}$, forced expiratory volume in $1 \mathrm{~s}$; FRC, functional residual capacity; F/S, fluticasone propionate/salmeterol; FVC, forced vital capacity; IC, inspiratory capacity; RVol, residual lung volume; TLC, total lung capacity; T/O, tiotropium/olodaterol.

\section{RESULTS}

Overall, 76 patients were randomised and treated across nine centres; 67 (88.2\%) completed all treatment periods. Most patients were male $(59.2 \%)$; mean age was 62 years. All patients were ex-smokers $(43.4 \%)$ or current smokers $(56.6 \%)$. Patients had mean FRC\% predicted of $146.8 \%$ and postbronchodilator $\mathrm{FEV}_{1} \%$ predicted normal of $52.9 \%$. Clinically stable comorbidities included hypertension $(61.8 \%)$, coronary artery disease $(9.2 \%)$, diabetes mellitus $(2.6 \%)$ and chronic cardiac failure $(2.6 \%)$ (table 1$)$.

At week 6, mean LVEDVI was increased from baseline $\left(66.644 \mathrm{~mL} / \mathrm{m}^{2}\right)$ by $2.317 \mathrm{~mL} / \mathrm{m}^{2}$ (95\% CI 0.061 to 4.574$)$ for $\mathrm{T} / \mathrm{O}$ and $2.855 \mathrm{~mL} / \mathrm{m}^{2}$ (95\% CI 0.597 to 5.112 ) for $\mathrm{F} / \mathrm{S}$. There was no significant difference between $\mathrm{T} / \mathrm{O}$ and $\mathrm{F} / \mathrm{S}$ (treatment difference (TD) $-0.537 \mathrm{~mL} / \mathrm{m}^{2} ; 95 \%$ CI -2.779 to $1.705 ; \mathrm{p}=0.6331$ ) (figure $1 \mathrm{~A}$ ). Neither treatment produced a significant change from baseline in aortic distensibility or pulmonary artery pulsatility. There were no significant TDs in other measures of cardiac function: $\mathrm{LV}$ or right ventricular (RV) end-systolic volume index, LV or RV ejection fraction, LV cardiac index, $\mathrm{LV}$ or RV stroke volume index, or LV or RV mass index (table 2).

FRC\% predicted was reduced from baseline by $10.211 \%$ with $\mathrm{F} / \mathrm{S}$ and $18.168 \%$ with $\mathrm{T} / \mathrm{O}$. There was a significant difference in favour of $\mathrm{T} / \mathrm{O}$, with a betweengroup difference of $-7.957 \%$ (95\% CI -12.865 to -3.050 ; $\mathrm{p}=0.0019$ ) (figure 1B). Absolute change from baseline in FRC (plethysmograph) was $-0.329 \mathrm{~L}$ with $\mathrm{F} / \mathrm{S}$ and $-0.581 \mathrm{~L}$ with $\mathrm{T} / \mathrm{O}$, with a between-group difference of $-0.252 \mathrm{~L}$ in favour of $\mathrm{T} / \mathrm{O}(95 \% \mathrm{CI}-0.413$ to -0.091 ; $\mathrm{p}=0.0028$ ) (figure 1B). There was also a larger reduction in RVol with $\mathrm{T} / \mathrm{O}(-0.572 \mathrm{~L})$ than with $\mathrm{F} / \mathrm{S}(-0.321 \mathrm{~L}$; TD $-0.251 \mathrm{~L} ; 95 \%$ CI -0.409 to -0.093 ; $\mathrm{p}=0.0024)$. Both drugs increased IC compared with baseline $(0.320 \mathrm{~L}$ and $0.289 \mathrm{~L}$ for $\mathrm{T} / \mathrm{O}$ and $\mathrm{F} / \mathrm{S}$, respectively) with no significant difference between treatments. There was a greater reduction in TLC with $\mathrm{T} / \mathrm{O}(-0.206 \mathrm{~L})$ than with $\mathrm{F} / \mathrm{S}$ $(-0.023 \mathrm{~L}$; TD between $\mathrm{T} / \mathrm{O}$ and $\mathrm{F} / \mathrm{S}-0.184 \mathrm{~L} ; 95 \%$ CI -0.358 to $-0.010 ; \mathrm{p}=0.0390$ ) (table 3 ).

$\mathrm{T} / \mathrm{O}$ was associated with larger improvements from baseline for $\mathrm{FEV}_{1}(0.339 \mathrm{~L}$ vs $0.158 \mathrm{~L}$ with F/S; TD $0.180 \mathrm{~L}$, $95 \%$ CI 0.121 to $0.240 ; \mathrm{p}<0.0001$ ), and for FVC $0.445 \mathrm{~L}$ vs $0.159 \mathrm{~L}$ with $\mathrm{F} / \mathrm{S}$; TD $0.286 \mathrm{~L}, 95 \%$ CI 0.171 to 0.400 ; $\mathrm{p}<0.0001)$.

Overall, the safety profile in the study was consistent with the known safety profile of both treatments.

\section{DISCUSSION}

To our knowledge, this is the first study to explore the effect of combining two bronchodilators versus an active treatment (LABA/ICS) on cardiac function. Both treatments improved LV function and decreased lung hyperinflation from baseline. Although $\mathrm{T} / \mathrm{O}$ provided greater improvements in lung hyperinflation than $\mathrm{F} / \mathrm{S}$ at week 6 , there was no significant between-treatment difference in LV or RV filling. While pulmonary function testing was performed with fixed timing 1.5 hours post-treatment, CMRI was conducted 1-8 hours post-treatment, which may partly explain the lack of difference in cardiac outcome compared with pulmonary function.

Two previous monocentric studies found improvements in hyperinflation that translated into increases in LV function, although neither used an active comparator. 
The CLAIM study showed a decrease in RVol with indacaterol/glycopyrronium, and a significant improvement in cardiac function versus placebo. ${ }^{7}$ Another study reported improved RVol with fluticasone furoate/vilanterol vs placebo, also translating into increases in RV and LVEDVI due to improved cardiac filling. ${ }^{8}$

The baseline LVEDVI and comorbid hypertension among patients in these studies was lower than in those in our study. Perhaps the mild severity of the analysed population in our study, with baseline mean LVEDVI of $66.64 \mathrm{~mL} / \mathrm{m}^{2}$, plus the higher prevalence of hypertension may have compensated for any between-treatment differences. In patients with COPD and lung hyperinflation, 6 weeks of treatment with $\mathrm{T} / \mathrm{O}$ or $\mathrm{F} / \mathrm{S}$ increased LVEDVI from baseline, with no statistically significant difference between treatments. However, $\mathrm{T} / \mathrm{O}$ resulted in a significantly greater reduction in lung hyperinflation versus $\mathrm{F} / \mathrm{S}$. Our finding that LAMA/LABA or LABA/ICS improve hyperinflation and cardiac function from baseline is consistent with previous studies. ${ }^{78}$

\section{Lay summary}

Many people with COPD die from heart disease. COPD causes air-trapping in the lungs (lung hyperinflation) and reduced filling of the bottom-left chamber (ventricle) of the heart. $\mathrm{T} / \mathrm{O}$ is an inhaled medicine that can make the lungs work more effectively, reduce breathlessness and improve quality of life by opening the airways in people with COPD.

We wanted to test if $\mathrm{T} / \mathrm{O}$ is better than another inhaler-F/S-in improving how the lungs and heart work. We measured the ability of patients to expel air as well as assessing changes in heart function using cardiac imaging techniques after 6 weeks of treatment.

We found that both $\mathrm{T} / \mathrm{O}$ and $\mathrm{F} / \mathrm{S}$ improved lung and heart function. Although $\mathrm{T} / \mathrm{O}$ did improve lung function by reducing lung hyperinflation more than F/S after 6 weeks, both treatments resulted in similar improvements in heart filling.

\section{Author affiliations}

${ }^{1}$ Department of Pneumology and Critical Care Medicine, ThoraxklinikHeidelberg GmbH, Translational Lung Research Center Heidelberg (TLRC), Heidelberg, Germany

${ }^{2}$ Biomedical Research in Endstage and Obstructive Lung Disease (BREATH) Fraunhofer Institute for Toxicology and Experimental Medicine ITEM, Hannover, Germany

${ }^{3}$ Department of Respiratory Medicine, Hannover Medical School, Hannover, Germany

${ }^{4} \mathrm{CIMS}$ Studienzentrum Bamberg GmbH, Bamberg, Germany

${ }^{5}$ TA CardioMetabolism Respiratory Medicine, Boehringer Ingelheim

International GmbH, Ingelheim am Rhein, Germany

${ }^{6}$ Boehringer Ingelheim Pharmaceuticals Inc, Ridgefield, Connecticut, USA

${ }^{7}$ Department of Radiology, Johannes Gutenberg University, Mainz, Germany

${ }^{8}$ Department of Medicine, Pulmonary and Critical Care Medicine, University

Medical Center Giessen and Marburg, Marburg, Germany

${ }^{9}$ Department of Diagnostic and Interventional Radiology, Hannover Medical

School, Hannover, Germany

${ }^{10}$ Pulmonary Research Institute, LungenClinic Grosshansdorf GmbH, Airway

Research Centre North (ARCN), Grosshansdorf, Germany
Acknowledgements Medical writing assistance, in the form of the preparation and revision of the manuscript, was supported financially by Boehringer Ingelheim and provided by Francesca Lomas at MediTech Media, under the authors' conceptual direction and based on feedback from the authors.

Competing interests FH reports personal fees from AstraZeneca, GlaxoSmithKline, Chiesi, Novartis, Boehringer Ingelheim, Olympus, Uptake, Erbe, BTG and Pulmonx outside the submitted work. JMH reports personal fees from Boehringer Ingelheim, CSL Behring, Merck\&Co and Novartis, as well as grant support for his institution from Allergopharma, ALK, Astellas, AstraZeneca, Boehringer Ingelheim, GlaxoSmithKline, Janssen, Leti, Novartis and Sanofi Aventis outside the submitted work. JH reports fees from AstraZeneca, Berlin Chemie, Boehringer Ingelheim and Novartis outside the submitted work. AdIH and XJ are employees or Boehringer Ingelheim. KFK has nothing to disclose. CFV reports personal fees from Almirall, Cipla, Berlin Chemie/Menarini, CSL Behring and Teva; grants and personal fees from AstraZeneca, Boehringer Ingelheim, Chiesi, GlaxoSmithKline, Grifols, Mundipharma, Novartis and Takeda; and grants from the German Federal Ministry of Education and Research (BMBF) Competence Network Asthma and COPD (ASCONET), Bayer Schering Pharma AG, MSD and Pfizer outside the submitted work. JVC reports personal fees from Boehringer Ingelheim, Siemens Healthineers, Bayer and Novartis, as well as grant support from Boehringer Ingelheim, Novartis, GlaxoSmithKline and Siemens Healthineers outside the submitted work. HW reports personal fees from AstraZeneca, Berlin Chemie, Boehringer Ingelheim, Chiesi, GlaxoSmithKline, Novartis and Roche outside the submitted work

Contributors The study was conceived and designed by FH, JH, HW and XJ. Patient data were collected by $\mathrm{FH}, \mathrm{JH}$ and $\mathrm{HW}$. The data were analysed by all co-authors (except $\mathrm{JH})$, and all authors were involved in interpreting the data. The initial draft was written by all authors, with all authors contributing revisions and approving the final draft.

Funding This study was supported by Boehringer Ingelheim Pharma GmbH \& Co. KG.

Ethics approval and patient consent All studies included in this analysis were performed in accordance with the provisions of the Declaration of Helsinki (1996 version), the International Conference on Harmonisation Tripartite Guideline for Good Clinical Practice, applicable regulatory requirements and Boehringer Ingelheim Standard Operating Procedures. All patients provided written informed consent. This article does not report individual patient data; all data presented here are anonymised. The clinical trial protocols and the informed consent and patient information forms were reviewed and received approval/favourable opinion from a constituted local Institutional Review Board or an Independent Ethics Committee at each centre prior to the start of the study. This study was approved by Ethikkomission Medizinische Heidelberg under ID number AFmu-559/2016.

Patient consent for publication Not required.

Provenance and peer review Not commissioned; externally peer reviewed.

Data availability statement Data are available from the corresponding author upon reasonable request.

Open access This is an open access article distributed in accordance with the Creative Commons Attribution Non Commercial (CC BY-NC 4.0) license, which permits others to distribute, remix, adapt, build upon this work non-commercially, and license their derivative works on different terms, provided the original work is properly cited, appropriate credit is given, any changes made indicated, and the use is non-commercial. See: http://creativecommons.org/licenses/by-nc/4.0/.

\section{REFERENCES}

1 Feary JR, Rodrigues LC, Smith CJ, et al. Prevalence of major comorbidities in subjects with COPD and incidence of myocardial infarction and stroke: a comprehensive analysis using data from primary care. Thorax 2010;65:956-62.

2 Fuhrman C, Jougla E, Nicolau J, et al. Deaths from chronic obstructive pulmonary disease in France, 1979-2002: a multiple cause analysis. Thorax 2006;61:930-4.

3 Rabe KF, Hurst JR, Suissa S. Cardiovascular disease and COPD: dangerous liaisons? Eur Respir Rev 2018;27:180057.

4 Watz H, Waschki B, Boehme C, et al. Extrapulmonary effects of chronic obstructive pulmonary disease on physical activity: a crosssectional study. Am J Respir Crit Care Med 2008;177:743-51.

5 Watz H, Waschki B, Meyer T, et al. Decreasing cardiac chamber sizes and associated heart dysfunction in COPD: role of hyperinflation. Chest 2010;138:32-8.

6 Blair HA. Tiotropium/olodaterol: a review in COPD. Drugs 2019;79:997-1008.

7 Hohlfeld JM, Vogel-Claussen J, Biller $\mathrm{H}$, et al. Effect of lung deflation with indacaterol plus glycopyrronium on ventricular filling in patients with 
hyperinflation and COPD (CLAIM): a double-blind, randomised, crossover, placebo-controlled, single-centre trial. Lancet Respir Med 2018;6:368-78.

8 Stone IS, Barnes NC, James W-Y, et al. Lung deflation and cardiovascular structure and function in chronic obstructive pulmonary disease. A randomized controlled trial. Am J Respir Crit Care Med 2016;193:717-26.

9 Wanger J, Clausen JL, Coates A, et al. Standardisation of the measurement of lung volumes. Eur Respir J 2005;26:511-22. 